Cuad. invest. hist., Brocar n. 15 (1989) Págs. 31-43

\title{
NOTAS SOBRE LA MECANIZACION DE LA PAÑERIA DE EZCARAY EN LA PRIMERA MITAD DEL SIGLO XIX
}

\author{
Ramón Ojeda San Miguel* \\ Universidad del País Vasco
}

\begin{abstract}
RESUMEN
En este artículo, básicamente fundamentado en fuentes de carácter cualitativo, tratamos de pasar revista al proceso de crecimiento y modernización del secular sector textil de Ezcaray. Sobre todo el que tuvo lugar aproximadamente los años 1800 y 1850 y que se centró en tres frentes simultáneos: mecanización de los procesos de producción, abaratamiento de los paños y mejoras en la calidad final de los productos.

Fundamentalmente repasamos el importante proceso de importación de maquinaria textil de origen europeo y la llegada de técnicos catalanes y europeos en la construcción de maquinaria. No obstante, pese a la importancia de la modernización, lo cierto es que la mecanización textil de esta zona riojana no fue, ni mucho menos, "perfecta».
\end{abstract}

In this article, mainly based on sources of qualitative character, we try to review the growth and modernization process of the textile sector in Ezcaray.

Specially the one that took place approximately in 1800 and 1850 and which was centred on three simultaneous fronts: mechanization of the production process, cheapening of cloths and improvements in the final quality of the product.

We mainly review the important process of textile machinery import of European origin and the arrival of technicians from Catalonia and Europe in the machinery-building.

Nevertheless, and besides the importance of modernization, the truth is that the textile mechanization in this Riojan area was not in the least "perfect».

* Dept. de Historia e Instituciones Económicas, Universidad del Pais Vasco, Facultad de H. ${ }^{a}$ y Geografia, Vitoria - Gasteiz. 


\section{R. OJEDA SAN MIGUEL}

La Rioja ha sido desde tiempos medievales una región con una clara trayectoria textil, especialmente visible en sus comarcas más montañosas: Cameros y cabecera del río Oja. La villa de Ezcaray y su comarca, la zona que ahora nos interesa, ya en el siglo $\mathrm{XV}$ era conocida como un importante centro pañero; eso sí, dedicado fundamentalmente a la fabricación de objetos baratos y de poca calidad.

A través de los numerosos trabajos hasta ahora publicados y por los documentos manejados por nosotros, es posible, aunque carecemos todavía de numerosos datos cuantitativos, realizar una aproximación a la evolución secular de esta tradicional comarca pañera ${ }^{1}$. Territorio que durante el siglo XVI conoció en su producción textil una etapa expansiva, además de procurar seriamente mejorar la calidad de sus paños. Tanto es así, que en esta centuria los textiles de Ezcaray eran fácilmente encontrados en la mayor parte de las ferias castellanas e incluso en las asturianas y gallegas. Como era de esperar, los pañeros ezcarayenses, sin embargo, estaban claramente controlados por el capital comercial, especialmente por los poderosos comerciantes de Burgos.

Aunque la carencia de documentos es especialmente grave para el siglo XVII, todo parece indicar que esta pañería atravesó por serias dificultades en esta centuria; hasta el punto de saber que a comienzos del siglo XVIII no era ni sombra de la conocida un siglo atrás. Decadencia que sigue siendo crudamente reflejada a mediados de este último siglo por el famoso Catastro del Marqués de la Ensenada.

Esta situación de decadencia arrastrada comenzó a cambiar, y casi de una forma radical, desde esas mismas fechas de mediados del siglo XVIII. Prácticamente todos los autores que han tratado el tema coinciden en responsabilizar de la reactivación pañera de esta comarca a la instalación de su célebre «Real Fábrica». A partir de esos momentos la Villa iba a conocer toda una serie de radicales transformaciones: el número de nacimientos comenzó a crecer con intensidad, aumentó el número de matrimonios y descendió la edad de las nuevas parejas, y comenzó a cristalizar una fuerte corriente de inmigrantes.

Como ya hemos indicado, fue la Real Fábrica la impulsora de esta reactivación, pero junto a ella surgieron multitud de pequeños talleres artesanales que volvieron a relanzar la producción pañera; tanto es así que, de nuevo, los textiles de Ezcaray vuelven a aparecer por casi todos los mercados peninsulares e incluso americanos.

La llegada del siglo XIX supuso la vuelta de los problemas para esta pañería, ahora mucho más graves, ya que el volumen de población dedicada a las actividades textiles era mucho mayor que en otras épocas, y la capacidad de producción también diametralmente superior.

En resumen, la segunda mitad del siglo XVIII inauguró una época de florecimiento, concretada en que no sólo hubo un proceso de crecimiento en la producción y calidad, sino que ya aparecieron claros síntomas de un verdadero proceso de modernización en el sector. El primer cuarto del siglo XIX estuvo plagado de dificultades, sobre todo en razón de la falta de salidas hacia el mercado para una pañería que ya contaba con una más que importante capacidad de producción, pero que sufría seriamente la competencia de los productos de otras zonas, mejores en calidad y con un nivel de precios más bajo. El mejor exponente de esta situación lo tenemos en el acuerdo firmado

1. Ojeda San Miguel, Ramón. Un documento para el análisis de una crisis textil: Ezcaray a comienzos del siglo XIX. Revista Estudios Regionales. Málaga (en prensa). En este trabajo se realiza una recopilación de los estudios hasta ahora publicados sobre la pañería de Ezcaray, por lo que en esta ocasión omitimos su cita y enumeración. 
por la mayor parte de los fabricantes en el año 1816, cuya finalidad era el establecimiento de unos acuerdos mínimos para intentar mejorar la calidad de los paños ${ }^{2}$.

Estaba claro, y es el tema fundamental que vamos a abordar en estas páginas, que toda la primera mitad del siglo XIX iba a suponer la lucha de la pañería del Alto Oja en tres frentes: seguir modernizando, mecanizando y hasta industrializando el sector; competir en precio con los paños de otras regiones, especialmente los catalanes; pero, sin embargo, intentar mantener las cotas de calidad que en otras épocas se habían llegado a alcanzar mediante métodos de fabricación entonces típicamente artesanales.

\section{CONSTRUCCION DE MAQUINAS}

Los años que marcan el paso del siglo XVIII al XIX suponen el intento de la pañería de Ezcaray por cambiar sus tradicionales métodos de fabricación por sistemas cada vez más mecanizados. Situación que puede quedar bastante bien resumida en estas palabras de Diego Ochagavía: «Desde fecha remota existían en este término regular número de talleres, muy rudimentarios, emplazados en plantas bajas de viviendas particulares y dedicados a la fabricación de paños que se hicieron famosos «por llevar el nombre del pueblo por todo el país». Al paso del tiempo fueron desapareciendo estas primitivas labores artesanas y concentrándose la producción en pequeñas industrias, que poco a poco fueron modernizando sus elementos de fabricación y adaptando las variantes de la hilatura de lanas...» $\aleph^{3}$.

Como ya hemos adelantado, está claro que el inicio de la mecanización del sector pañero del Alto Oja tuvo sus primeros gérmenes en la introducción de algunas máquinas por parte de la Real Fábrica de Ezcaray. Sin embargo, este hecho supuso que muchos pequeños fabricantes vieran las ventajas de una posible mecanización, y que se lanzasen a lo largo de la primera mitad del siglo XIX, bien individualmente o en pequeñas compañías, a un compra generalizada de máquinas cada vez más sofisticadas.

Ante la alarmante carencia de documentos de carácter municipal, para intentar aproximarnos a este tema de la mecanización de la pañería de Ezcaray, hemos rastreado los fondos notariales de esta Villa, depositados en el archivo provincial de Logroño. Es evidente, cosa que cualquier persona mínimamente familiarizada con este tipo de documentación conoce, que no todas las compras y contratos de construcción de maquinaria textil se recogen y se protocolizaron en la misma Ezcaray. No obstante, los documentos notariales encontrados durante la primera mitad del siglo XIX sí nos sirven como exponente revalizador del fenómeno antes apuntado de la mecanización de una vieja industria.

En concreto, entre los años 1809 y 1844 aparecen un total de 24 escrituras para la construcción y compra de nueva maquinaria. Como luego podremos comprobar, bastante fue fabricada en los talleres y fraguas de la propia Ezcaray; mientras que su destino no siempre llevó idéntica dirección: 14 estaban destinadas a ser instaladas allí mismo, tres en Valgañón, dos en Canales, dos en Pradoluengo, y otras tres salieron con destino a Torrecilla, Burgos y Rioseco. Algo, esto último, que ya ha sido puesto de

2. Ibídem.

3. Ochagavía, Diego. Notas para la Historia textil riojana. Berceo V, I y II. Años 1946 y 1947, pp. 222. 
manifiesto por otros autores conocedores de la región: «consta que de Ezcaray salieron maquinarias y oficiales para establecer talleres y fábricas en Torrecilla y Soto en Cameros, Santo Domingo de la Calzada, Valgañón y otras regiones de España»4.

La mayoría de las escrituras de construcción maquinista utilizadas por nosotros se concretan en casos de cardadoras, perchadoras y en el proceso de la hilatura. En total aparecen, aunque muchos se repiten, 25 nombres de constructores de maquinaria textil. De ellos, y esto es realmente muy importante para comprender los orígenes de la mecanización real en Ezcaray, 12 nombres son originarios de los Países Bajos, 8 de la propia localidad, 4 catalanes y otro de una comarca muy cercana.

Los primeros en aparecer, lo que, recalcamos, demuestra el primitivo origen de la maquinaria llegada a Ezcaray, fueron los constructores de máquinas catalanes. En concreto, nuestra documentación notarial señala la llegada de dos expertos desde el Principado. El primero fue Francisco Coll, avecindado en la localidad de Olot, quien en el año 1815 se comprometió a fabricar «las máquinas necesarias para hilar, hacer cardas y demás necesarias a la fabricación de paños finos» ${ }^{5}$ para la sociedad establecida entre D. Juan Pablo Texada y Benito y D. Luis Murgón y Armada. Este mismo maquinista se comprometió también un año después a fabricar diferentes artefactos para el establecimiento pañero de D. Torivio Gonzalo, D. Casimiro Herrán y D. Julián Pérez. «Como inteligente en la materia», el citado Coll se responsabilizó de la construcción de «un juego de Máquinas que se deve componer a saver: de una de Emborrar, otra de cardar, otra de Letas y cinco de Ylar. (...) Que de cuenta del mismo Francisco ha de ser la dirección del Arbol, rueda y demás necesario para que anden las expresadas máquinas por agua segun las de Perchar y Tundir...»\%. A cambio de todo ello los pañeros ezcarayenses habían de proporcionar al profesor catalán un taller, una casa para vivienda, 32 reales diarios y 8.000 reales al finalizar las obras ${ }^{7}$. Muy bien le debieron ir las cosas a este constructor puesto que sabemos que todavía en el año 1824 seguía residiendo en la Villa, y que llegó a fomar una sociedad con el vecino de la misma D. José Hernáinz para la fabricación de paños: «Que el primero tiene construido en la propia de Ezcaray, y sitio que llaman del campo de la Fábrica un edificio para máquinel que de su propiedad tiene andante un juego, mas siendo el local suceptible de colocar otro de su cuenta, y que corran los dos en sociedad y compañía a ganancias y pérdidas iguales...». En este caso Coll se responsabilizará de la fabricación de las máquinas, desempeñando también el cargo de contramaestre de la Fábrica por un mínimo de cinco años ${ }^{8}$.

4. García San Lorenzo Mártir, Fray José. Ezcaray. Su Historia. Logroño 1959, p. 76.

5. Archivo histórico provincial de Logroño (en adelante A.H.P.L.). Protocolos notariales de Ezcaray. Santiago Manuel González Herreros. Sig. 2947, año 1815, fol. 31. «Poder de D. Pablo Texada y D. Luis Murgón» (26/IV/1815).

6. Ibídem. Prot. not. Ezcaray. Basilio de Mata. Sig. 3170, año 1816, fol. 108 y 109. «Combenio entre Francisco Coll de Olot, en Cataluña, profesor de máquinas, de una parte, y de la otra D. Torivio Gonzalo y D. Casimiro Herrán, por sí, y a nombre de D. Julián Pérez, vecinos de esta Villa. Para la construcción de un juego, o más, de máquinas de Emborrar, cardar, Letas e Ylar que se han de fixar en esta Villa, en establecimiento y Edificio a propósito, y han de andar por agua» (26/VIII/1816).

7. Ibídem.

8. Ibídem. Prot. not. Ezcaray. Santiago Manuel González Herreros. Sig. 2947, año 1824, fol. 5 y 6. «Escritura de convenio entre D. José Hernáinz, y Francisco Coll, vecinos de Ezcaray» (8/VIII/1824). 
Por el mismo tiempo en que llegó este primer maquinista apareció el también catalán Antonio Petit, avecindado esta vez en Tarrasa y titulado en la documentacion como «Profesor de máquinas». En el año 1816 se concertó con los ya conocidos fabricantes de textiles Gonzalo, Herrán y Pérez a fabricar en la misma Cataluña, en el período de tan sólo 70 días, "varias máquinas de tundir, y las de la percha de revesillo y tirado correspondientes». Pero como era lógico, los empresarios riojanos también necesitaban que alguien pusiera en funcionamiento y gobernara las nuevas máquinas, por eso «Han tratado las dos partes en poner, y tener corrientes en esta Villa por espacio de ocho años varias máquinas de tundir, y las de percha de rebesillo, y tirado correspondientes dispuestas por el recordado Antonio como inteligente en la materia. Que ha de tener corrientes las máquinas de tundir de nueve tixeras, y la de la Percha, y tirado correspondientes, ambas por agua, enseñando a los que las manejen, de suerte que aunque falte del pueblo puedan ser bien desempeñadas». Además Petit admitía «Que ha de ser de su obligación el construir los juegos que hagan falta para la Compañía» y «Que ha de poner corrientes todos los juegos de tundir y perchar que se ajusten así para este pueblo como fuera de él...» ${ }^{10}$. Como contrapartida recibirá 20 reales diarios mientras estuviera en Tarrasa haciendo las máquinas, se le pagaría el viaje de ida y vuelta, y durante su estancia en Ezcaray recibiría la tercera parte de todas las utilidades surgidas en los nuevos establecimientos ${ }^{11}$.

Otros catalanes, aunque no directamente para construir máquinas, también llegaron a Ezcaray para gobernar los instrumentales técnicos de algunas fábricas y para enseñar su manejo a los naturales del País. Este es, por ejemplo, el caso de la familia de Pedro Torras, «naturales de Balsareny y Obispado de Vick», quien llegó «para cuidar y dirigir unas máquinas de cardar, emprimar, merchar e Ylar lana», ya «Que dho maestro Torras ha de enseñar a cardar, emprimar, merchar e Ylar, como así bien la dirección, y el manejo de las prenotadas máquinas» ${ }^{12}$.

Es evidente, por tanto, que los fabricantes riojanos de paños del Alto Oja conocían y sufrían, perfectamente en la segunda década del siglo XIX que Cataluña era la región pionera en los avances técnicos del sector textil español, y que si se quería seguir subsistiendo había que tomarla como el modelo a imitar. En este sentido, es ya de sobra conocido que el algodón posibilitó durante las últimas décadas del siglo XVIII el comienzo de la mecanización de los textiles catalanes ${ }^{13}$. El desarrollo técnico de la fabricación

9. Ibídem. Prot. not. Ezcaray. Basilio de Mata. Sig. 3170, año 1816, fol. 106 y 107. «Combenio entre Antonio Petit, vecino de Tarrasa en Cataluña, profesor de Máquinas, de una parte, y de la otra D. Torivio Gonzalo y D. Casimiro Herrán, por sí y a nombre de Julián Pérez, vecinos de esta Villa, por la egecución de varias máquinas de tundir, y las de percha de revesillo y tirado correspondiente, que se han de fixar en esta Villa en establecimiento y Edificio a propósito, y han de estar corrientes por agua, por tiempo de ocho años, o menos según acordaren las partes» (27/VII/1816).

10. Ibídem.

11. Ibídem.

12. Ibídem. Prot. not. Ezcaray. Basilio de Mata. Sig. 2585, año 1817, fol. 91 y 92. «Combenio y obligación entre partes, de la una D. Juan Pablo de Texada y Benito, vecino de esta Villa de Ezcaray, y de otra Pedro Torras y Mariana Algués, su mujer, residentes en la misma, de oficio ylan ylanderos de lana en máquina. Para cuidar y dirigir unas máquinas de cardar, emprimar, merchar e Ylar lana (costeadas por dho D. Juan Pablo, a expensas suyas) el insinuado Torras como tal maestro Ylandero, y prestar el travaxo a ellas, con la mencionada su muger y sus tres hixos menores, llamados Josef, Marcos y Pablo, por tiempo de cinco años, que empiezan a correr desde el día de la fecha» (1/III/1817).

13. Nadal Oller, Jordi. La Economía epañola (1829-1931), dentro de la obra «El Banco de España. Una Historia Económica». Madrid 1970, pp. 337-339. 


\section{R. OJEDA SAN MIGUEL}

de textiles de algodón en Cataluña provocó también la paulatina mecanización del sector lanero, que «ya venía gestándose desde finales del siglo XVIII» ${ }^{14}$.

Según indican las últimas investigaciones catalanas, las llaves del éxito lanero de aquella zona peninsular radicaron casi desde un principio en tres clarísimos factores: en la mecanización, que posibilitó la obtención de productos más baratos y competitivos; en la especialización de paños finos y artículos de novedad; y, por último, en la constante preocupación de los fabricantes catalanes por la moda ${ }^{15}$. En medio de estas coordenadas pronto surgieron allí grandes y modernos centros pañeros. Por ejemplo, en Tarrasa «las cardas antiguas, los tornos de hilar, los telares manuales y los batanes de noguer o de mazas, van dejando paso a las cardas de «xapo», a las cardas de «araña», a las «mulejennies» y a las selfactinas, a los telares mecánicos y a los batanes cilíndricos» ${ }^{16}$. Semejante a lo ocurrido en Sabadell, otro de los importantes centros pañeros catalanes, donde después de las guerras napoleónicas, y la pérdida de las colonias americanas, se luchó encarnizadamente por la conquista del mercado español, para lo cual se empezó a mecanizar el sector, comenzando dicho proceso por las operaciones de la hilatura ${ }^{17}$.

No resulta pues raro que los fabricantes de Ezcaray se dieran cuenta de que no bastaba, como lo estaban haciendo desde el siglo anterior, con producir mayores cantidades de productos y lanzarlos al mercado. Los catalanes sabían que uno de sus grandes mercados, el mismo que el de los paños riojanos, era el castellano, y que para su conquista había que producir a precios competitivos, pero a la vez cuidando cada vez más su calidad. Para la consecución de estos objetivos era necesario estar a todo trance en la cresta de la ola llamada mecanización. En esta carrera los catalanes salieron antes, pero otros centros, como el de Ezcaray, intentaron seguirles.

Los productores ezcarayenses, que pasaban por un serio problema de pérdida de calidad y apreciación de sus textiles, está claro que quisieron seguir el ejemplo catalán. Por ello se contrataron los servicios de especialistas catalanes en la construcción de maquinaria textil, con seguridad más de los que nosotros hemos localizado en la documentación notarial, además de preocuparse por aprender a construirla y a gobernarla. Con los catalanes, por lo tanto, empezaron a surgir en Ezcaray especialistas y pequeños talleres de construcción maquinista. Se empezaron a generalizar los avances técnicos en las tareas del cardado, emborrado, hilado y tundido. Curiosamente, y éste será uno de los lastres más importantes de Ezcaray a lo largo de casi toda la centuria, la mecanización de los telares fue casi inexistente. Por último, hay que señalar que también fueron los catalanes los que trajeron a Ezcaray, no se olvide comarca mal comunicada con los centros de aprovisionamiento carbonífero, los necesarios conocimientos técnicos para poder utilizar la fuerza impulsora de la energía hidráulica.

En esta carrera por competir en los mercados interiores en calidad y precio, después de la llegada de catalanes, también comenzaron a llegar a esta comarca constructores de

14. Varios. Catalunya la fábrica d'Espanya (1833-1936). Un siglo de Industrialización catalana. Barcelona 1985 , p. 77.

15. Ibídem. p.77.

16. Ibídem. p.78.

17. Camps Cura, Enriqueta. Industrialización y crecimiento urbano: la formación de la ciudad de Sabadell. Revista de Historia Económica. Año V, invierno de 1987, no 1, p. 52. Esta localidad, al igual que Tarrasa, a lo largo de la primera mitad del siglo XIX, introdujo nuevas técnicas que requerían modestas cantidades de capital fijo, y se fue especializando cada vez más acentuadamente en la obtención de paños de calidad media y alta (p. 54). 
máquinas europeos. Desde comienzos de los años veinte tenemos ya constancia de este hecho, especialmente referido a varios maquinistas provenientes de los Países Bajos. La primera referencia la tenemos en el caso de un especialista, llamado Luis Boulandie, residente en Ezcaray en el año $1822^{18}$, al parecer conocedor de los avances técnicos del proceso en el cardado de la lana. Personaje al que volveremos a encontrar en el año 1833 gobernando «un juego y medio de cardas y los seis tornos de ilar» en el establecimiento de Hernáinz ${ }^{19}$.

Revolucionaria iba a resultar para Ezcaray la presencia desde comienzos de los años treinta de los hermanos Lamberto y Nicolás Dumoulin, naturales de «Dijon en el Reyno de Bélgica» ${ }^{20}$. Ambos maquinistas se avecindaron definitivamente en la villa de Ezcaray, convirtiéndose en verdaderos maestros de futuros especialistas y propagadores de muchas novedades técnicas por toda la comarca. Parece ser que una de sus más importantes primeras obras se escrituró en el año 1834, momento en el que se comprometieron a construir unas máquinas de cardar e hilar para el fabricante Carlos Sáenz. La documentación es en este caso bastante esclarecedora de las capacidades técnicas traídas a Ezcaray: «Que dhas máquinas han de constar de dos cardas, una para emborrar, y otra para emprimar, cuatro tornos para hilar fino de sesenta usos cada uno, un torno de merchar, compuesto de cuarenta usos, un Diablo de aumento suceptible de dar la labor bien y para tres juegos, dos aspas con la medida a la catalana, cuatro esmeriles de cuatro caras para gobierno de dhas máquinas, una llave inglesa de un pie cumplido y las demás de costumbre con los usos de costumbre para las aspas (...). Que las máquinas han de ser hechas a la catalana y montadas a la francesa, pero los tornos de hilar y nerchar han de estar montados a la francesan" ${ }^{21}$.

Juntos construyeron también varias máquinas de cardar e hilar para el establecimiento pañero que su hermano Juan José tenía en Ezcaray en el año $1835^{22}$, y otro juego de la misma naturaleza para la fábrica de Carlos Sáenz en aquel mismo año ${ }^{23}$.

También trabajaron abundantemente por separado. Por ejemplo, Lamberto Dumoulin sabemos que para el establecimiento conocido de Sáenz construyó una percha por 1.200 reales en el año $1832^{24}$, y por otros 3.300 reales «una letera para cardar lana que ha de estar montada sobre cercos y rasos de fierro» en $1836^{25}$. Como ya antes

18. A.H.P.L. Prot. not. Ezcaray. Basilio de Mata. Sig. 3021, año 1822, fol. 134 y 135. Obligación (22/VIII/1822).

19. Ibídem. Prot. not. Ezcaray. Hermenegildo García. Sig. 2908, año 1833, fol. 1 y 2. «Escritura de obligación» (1/I/1833). Y Sig. 2.908, año 1833, fol. 33 y 34 . «Convenio» (1/III/1833).

20. Ibídem. Prot. not. Ezcaray. Santiago Manuel González Herreros. Sig. 2889, año 1835, fol. 38. Declaración $(7 / \mathrm{III} / 1835)$.

21. Ibídem. Prot. not. Ezcaray. Santiago Manuel González Herreros. Sig. 2889, año 1834, fol. 49. «Escritura de obligación contra Lamberto José Dumoulin y su hermano de Ezcaray, y Carlos Sáenz Arroyo de la misma vecindad» (7/VV/1834). La obra duró un año con un presupuesto de 23.000 reales. 38.

22. Ibídem. Prot. not. Ezcaray. Santiago Manuel González Herreros. Sig. 2889, año 1835, fol.

23. Ibídem. Prot. not. Ezcaray. Santiago Manuel González Herreros. Sig. 2889, año 1835, fol. 136 y 137. Compromiso (20/X/1835).

24. Ibídem. Prot. not. Ezcaray. Santiago Manuel González Herreros. Sig. 2889, año 1832, fol. 78. «Escritura de obligación de hacer una percha por Lamberto José Dumoulin en 1.200 reales para Carlos Sáenz» (9/VI/1832).

25. Ibídem. Prot. not. Ezcaray. Santiago Manuel González Herreros. Sig. 2763, año 1836, fol. 40. «Convenio para construir una máquina por Lamberto Dumoulin para Carlos Sáenz» (2/V/1836). 
adelantábamos, igualmente construyeron máquinas para otras localidades; así, Lamberto realizó para una compañía pañera de Canales en el año 1830 «una máquina de cardar e hilar lana, compuesta de una emborradora con cardas, una Letera con los mismos, un Diablo, un torno de merchar, quatro tornos para fino y dos aspas con el correaje correspondiente y necesario ${ }^{26}$. También para el fabricante de Canales Benito González realizó tres años después una máquina «Transversal» con una percha de 18 palmares ${ }^{27}$. Por último, tenemos la constancia de que en el mismo año fabricó para varios pañeros de Valgañón «un juego de máquinas de cardar e hilar» movidas por sangre ${ }^{28}$.

Por su parte Nicolás Dumoulin fabricó para el establecimiento pañero de Ezcaray, conocido como el «Molino de San Miguel», una «rueda para el movimiento de las máquinas $»^{29}$ y «una máquina de perchar paños» ${ }^{30}$ en el año 1832. Asimismo, para el fabricante ezcarayense Fermín Gonzalo de Soto realizó un año después «una máquina idéntica a la que Dumoulin ha construido para la Real Fábrica de esta Villa» ${ }^{3 !}$.

Al igual que su hermano, Nicolás Dumoulin levantó máquinas para otras localidades. En 1831, y para el fabricante burgalés José Torres Casado, realizó «medio juego de máquinas compuesto de un Diablo, una emborradora con dos descargadores, una Letera, una merchera de cuarenta usos, dos tornos de sesenta usos cada uno, una aspa, y el movimiento necesario para enganchar con caballerías» ${ }^{32}$. De nuevo en 1835 construyó «un juego de máquinas de cardar e hilar lana, con el movimiento necesario para que ande por agua» para una fábrica de Pradoluengo ${ }^{33}$.

Por otra parte, sabemos que estos constructores belgas no se conformaron con mantener talleres metalúrgicos, sino que también se animaron durante los años cuarenta a levantar sus propias fábricas de paños en la villa de Ezcaray, lugar en el que se quedaron definitivamente a residir.

Los hasta ahora estudiados fabricantes belgas, no fueron los únicos extranjeros llegados a esta comarca para construir máquinas. En la década de los años treinta trabajaron en Ezcaray los maquinistas franceses Francisco Vicheran y Alejandro Alemán ${ }^{34}$. Pero lo más importante, por las consecuencias que a la larga produjo, estuvo

26. Ibídem. Prot. not. Ezcaray. Santiago Manuel González Herreros. Sig. 2636, año 1830, fol. 18 y 19. Escritura con José González Rocandio, Dionisio Calbo Sáenz, José Robredo y Marcos Prado (27/II/1830). El precio de la máquina se estableció en 28.250 reales.

27. Ibídem. Prot. not. Ezcaray. Hermenegildo García. Sig. 2908, año 1833, fol. 14. Contrata $(19 / \mathrm{I} / 1833)$.

28. Ibídem. Prot. not. Ezcaray. Santiago Manuel González Herreros. Sig. 2763, año 1836, fol. 10. «Escritura de convenio entre Lamberto José Dumoulin de una parte, y de la otra Manuel Eterna, Pedro Apestegui, Juan Peña y León Elías» (10/L/1836).

29. Ibídem. Prot. not. Ezcaray. Hermenegildo García. Sig. 2908, año 1832, fol. 175. Obligación $(9 / \mathrm{XI} / 1832)$. La obra se tasó en la cantidad de 2.200 reales.

30. Ibídem. Prot. not. Ezcaray. Hermenegildo García. Sig. 2908, año 1832, fol. 179 y 180. Contrata (16/XII/1832). El valor fue de 800 reales.

31. Ibídem. Prot. not. Ezcaray. Hermenegildo García. Sig. 2908, año 1833. Contrata (25/III/1833)

32. Ibídem. Prot. not. Ezcaray. Santiago Manuel González Herreros. Sig. 2636, año 1831, fol. 41 y 42. «Escritura de obligación para hacer medio juego de máquinas, que otorga Juan Nicolás Dumoulin, vecino de Ezcaray en favor y para José Torres Casado de Burgos en 20.000 reales de vellón» $(12 / \mathrm{III} / 1831)$.

33. Ibídem. Prot. not. Ezcaray. Santiago Manuel González Herreros. Sig. 2889, año 1835, fol. 151 y 152. "Convenio entre Juan Nicolás Dumoulin y Andrés Alcalde, Antonio Martínez y otros» (20/XII/1835). La obra se tasó en 32.000 reales de vellón.

34. Ibídem. Prot. not. Ezcaray. Santiago Manuel González Herreros. Sig. 2889, año 1835, fol. 136 y 137 . Compromiso $(20 / \mathrm{X} / 1835)$. 
en que todos estos especialistas foráneos crearon una verdadera escuela de técnicos autóctonos. A este respecto conocemos algunos de sus nombres; por ejemplo, Florencio Castro quien, formado en el taller de Lamberto Dumoulin ${ }^{35}$, en el año 1831 construyó para el conocido pañero Carlos Sáenz «una máquina transversal o tundidora (...), como lo están las transversales francesas, que están corrientes en este pueblo» ${ }^{36}$, y junto al también maquinista Marcelino Campo montó en Soto de Cameros «una máquina de lustrar paños o prensa lustrosa» en el año $1843^{37}$. Otros constructores de máquinas ezcarayenses fueron Gaspar de Urieta ${ }^{38}$, Atanasio Ibarra $^{39}$, José Handeta ${ }^{40}$, Policarpo Grijalva $^{41}$, Antonio Aguirre, Marcelino Ibáñez y Francisco Onandía ${ }^{42}$.

Incluso, nos podemos encontrar con casos tan especiales como el reseñado en 1827 , cuando el importante fabricante Casimiro Herrán nombraba a su hijo Felipe director de los tintes de su establecimiento, atendiendo a su experiencia «por haberla adquirido en los muchos años que ha residido en Francia, cursando las ciencias del arte, en el que se halla aprobado» ${ }^{43}$. Sin duda una prueba más del interés de los fabricantes riojanos por imitar los sistemas de fabricación y adelantos técnicos de los países más desarrollados de Europa.

\section{IMPORTACION DE MAQUINARIA}

Como por otra parte resulta lógico, no solamente a Ezcaray llegaron técnicos foráneos para montar máquinas, sino que además muchas de éstas se importaron masivamente desde Europa.

De nuevo el primer motor de todo este proceso arranca desde mediados del siglo XVIII con la instalación de la Real Fábrica de Santa Bárbara, época en que se trajeron a

35. Ibídem. Prot. not. Ezcaray. Santiago Manuel González Herreros. Sig. 2636, año 1830, fol. 18 y 19 . Escritura $(27 / \mathrm{IU} / 1830)$.

36. Ibídem. Prot. not. Ezcaray. Santiago Manuel González Herreros. Sig. 2636, año 1831, fol. 35 y 36. «Combenio entre Carlos Sáenz Arroyo y Florencio Castro» (23/II/1831). El compromiso señalaba que la máquina se realizaría en 45 días por el precio de 8.000 reales de vellón.

37. Ibídem. Prot. not. Ezcaray. Hermenegildo García. Sig. 2922, año 1843, fol. 84. «Convenio y obligación entre Florencio Castro y Marcelino Campo, vecinos de esta Villa, y D. Felipe Herbías vecino de Soto de Cameros» (19/VI/1843).

38. Ibídem. Prot. not. Ezcaray. Santiago Manuel González Herreros. Sig. 2889, año 1832, fol. 123. «Poder otorgado por D. Gaspar Ureta, de este domicilio, en favor de Juan Nicolás Dumoulin de la misma vencidad» $(9 / \mathrm{XI} / 1832)$.

39. Ibídem. Prot. not. Ezcaray. Santiago Manuel González Herreros. Sig. 2889, año 1835, fol. 136 y 137.

40. Ibídem. Prot. not. Ezcaray. Santiago Manuel González Herreros. Sig. 2763, año 1836, fol. 40. «Convenio para construir una máquina por Lamberto Dumoulin para Carlos Sáenz» (2/V/1836).

41. Ibídem. Prot. not. Ezcaray. Hermenegildo García. Sig. 2922, año 1844, fol. 93. "Contrato entre partes, de la una Policarpo Grijalva y de la otra D. Indalecio Mingo, D. Pedro Fuentes y D. Bernardo Regúlez, vecinos el $1 .^{\circ}$ de esta Villa y los $2 .^{\circ}$ de Pradoluengo para la construcción del fierro necesario para unas máquinas, en precio de 10.050 reales» (16/III/1844).

42. Ibídem. Prot. not. Ezcaray. Hermenegildo García. Sig. 2922, año 1844, fol. 39. «Poder otorgado por Antonio Aguirre, Mariano Ibáñez y Francisco Onandía, vecinos de esta Villa, a favor de D. Antonio García Navarro de la ciudad de Rioseco, para que liquide y reclame el cumplimiento de la contrata que celebraron con D. León Puerta de dho Rioseco sobre la venta de máquinas» $(3 / \mathrm{IL} / 1844)$.

43. Ibídem. Prot. not. Ezcaray. Santiago Manuel González Herreros. Sig. 2663, año 1827, fol. 72. «Escritura de convenio entre D. Casimiro Herrán e hijo» (16/VIII/1827). 


\section{R. OJEDA SAN MIGUEL}

la Villa operarios franceses, ingleses, irlandeses y máquinas desde el exterior ${ }^{44}$. Este proceso se aceleró a partir del año 1785, cuando la Real Fábrica pasó a ser controlada por los Cinco Gremios Mayores de Madrid, y se trajeron numerosas máquinas textiles desde Lieja a través del puerto de Bilbao, con la clara intención de imitar los productos europeos más en voga ${ }^{45}$.

A estas primeras importaciones siguieron otras muchas, realizadas ahora por numerosos pequeños fabricantes de la localidad. La mayor parte de ellas comenzaron a partir de los años veinte del siglo XIX, momento, como ya hemos visto, en que los fabricantes riojanos emprenden un intento casi desesperado por mejorar la calidad de sus productos. Contamos, en base siempre a la documentación de carácter notarial, con varias referencias en este sentido. Así por ejemplo, el importante pañero D. Casimiro Herrán trajo en el año 1821 una máquina de emborrar, desembarcada en Bilbao, desde los Países Bajos ${ }^{46}$.

La demanda de máquinas europeas debió ser tan alta que incluso llegaron a instalarse en la propia Ezcaray varios intermediarios extranjeros, cuyo negocio estuvo siempre en sus contactos para poder importar diferentes artefactos con garantías. Sin duda, el más activo de todos ellos fue Pedro Alexandro Sanelain Aleman, «hijo legítimo de D. Ramón Alemán y de Anna de Mausein, vecinos de la villa de Sette Departamento de L'heraut $\rangle^{47}$. Personaje de origen francés que ya estaba instalado y avecindado en Ezcaray en los años veinte. Por ejemplo, en este caso concreto sabemos que en 1827 hizo traer para la fábrica de D. Juan Manuel González una máquina transversal y doce tijeras de tundir, «que por pedido suio hizo venir de la casa Chokeril, en Francia»" ${ }^{48}$. Este mismo importador nos aparece en 1840 asociado con Francisco Bicheraux, momento en que se obligan «a traer, y hacer traer de su cuenta y riesgo para D. Santiago Martínez Pinillos, vecino de Torrecilla de Cameros, un juego completo de máquinas de cardar e hilar lana (...), deviendo venir las cardas de Bélgica, todo a un precio de cuarenta y cuatro mil reales ${ }^{49}$, todo lo cual llegaría por mar hasta el puerto de Bilbao, Santander o Bayona.

Ya hemos comentado anteriormente que esta fiebre importadora fue especialmente intensa en los años veinte. Hasta el punto de tener la constancia de que en el año 1829

44. García de San Lorenzo Mártir, Fray José. Ob. cit. p. 73.

45. Ibídem. pp. 74-75.

46. A.H.P.L. Prot. not. Ezcaray. Basilio de Mata. Sig. 3021, año 1821. «Obligación de Benito Pasqual, vecino de Monasterio de Rodilla, y Benito Valgañón de Santa María de Cubo a D. Casimiro Herrán, vecino de esta villa de Ezcaray, de estar a resultas de la havería que ha padecido una pieza de máquina, titulada tambor de la de emborrar, recivida en Bilbao, por Pasqual y Valgañón, y conducida a esta villa de Ezcaray, al establecimiento del D. Casimiro» (14/VIII/1821).

47. Ibídem. Prot. not. Ezcaray. Santiago Manuel González Herreros. Sig. 2889, año 1843, fol. 71. «Testamento otorgado por D. Alejandro Alemán y Da Estefanía Herrán su muger en Ezcaray» $(15 / \mathrm{IX} / 1834)$.

48. Ibídem. Prot. not. Ezcaray. Basilio de Mata. Sig. 2701, año 1827, fol. 42. «Poder de D. Juan Manuel González, vecino de Ezcaray, a D. Manuel Valle, de la misma vecindad, y a D. Juan de Marroquín, procurador en Burgos, para seguir la demanda introducida contra D. Alexandro Alemán, tamvién vecino de Ezcaray, sobre que reciva y paque una máquina llamada Trasversal y doce tigeras de tundir por él pedidas» (16/VIIJ/1827). La máquina costó 22.000 reales (Santiago Manuel González Herreros. Sig. 2663, año 1827, fol. 86. «Escritura de transacción entre D. Manuel Valle y D. Alejandro Alemán»).

49. Ibídem. Prot. not. Ezcaray. Santiago Manuel González Herreros. Sig. 2763, año 1840, fol. 31. «Escritura de obligación entre D. Alejandro Alemán y D. Santiago Martínez» (7/X/1840). 
un total de 18 fabricantes de esta comarca de Ezcaray habían importado maquinaria, puesto que pleiteaban en Santo Domingo de La Calzada «para no pagar el 10 por ciento que se les exige por introducir maquinaria del Exterior del Reino» ${ }^{50}$.

La mayoría de las máquinas, si nos atenemos a lo que manifiestan nuestras fuentes notariales, llegaron desde Francia y sobre todo de los Países Bajos. Pongamos otro ejemplo muy esclarecedor: en 1829 la sociedad pañera de «Gonzalo, Mendiola y Sáenz» hizo venir «dos máquinas de perchar (...), una máquina de cepillar paños, ocho mesas de tundir paños con quince tijeras, un desmolique con sus llaves y calibres, una tundidora transversal con su cilindro supernumerario, y la caja de herramientas, todo lo que han comprado (...) a D. Juan Bautista Kaufman, vecino de Lieja en los Países Bajos $\aleph^{51}$, utilizando como intermediario a «D. Carlos Bicheraop, vecino de Lieja en los Países Bajos, residente en esta, apoderado general de D. Juan Bautista Kaufman $»^{52}$. Como se puede apreciar, este caso pone de manifiesto que la demanda de maquinaria llegó a ser tan intensa, que incluso algunos fabricantes europeos colocaron en Ezcaray a sus propios agentes.

Seguramente los ejemplos, utilizando otro tipo de fuentes, se podrían multiplicar; pero nosotros solamente tenemos la constancia de que todavía en los años cuarenta residía en Ezcaray el francés Pablo Julio Allonard asociado con el vecino Gregorio de La Torre para la introducción de máquinas ${ }^{53}$, y el también posiblemente galo Eugenio Cisterne ${ }^{54}$.

\section{BATANES}

Este aumento del número de máquinas textiles, y por lo tanto de la capacidad de producción, dio lugar también a que fuesen mayores las necesidades de abatanado. Si tenemos en cuenta que la ubicación de los batanes o pisones de paños requería la presencia de cuando menos medianas corrientes de agua, comprenderemos el hecho de que los fabricantes de Ezcaray se lanzaran a partir de los años veinte a construirlos en los ríos de las localidades próximas. Máxime cuando las aguas de Ezcaray, desde hacía muchos años, estaban utilizadas casi al cien por cien de sus posibilidades: florecientes ferrerías y fraguas desde el siglo XVIII, molinos, talleres metalúrgicos y las numerosas máquinas textiles montadas a base de energía hidráulica.

50. Ibídem. Prot. not. Ezcaray. Santiago Manuel González Herreros. Sig. 2636, año 1829, fol. 229. «Poder otorgado por D. Manuel del Valle y Consortes, vecinos de esta villa de Ezcaray en favor de D. Francisco Javier Gárate, vecino de La Calzada» (20/VII/1829). Los fabricantes eran los siguientes: Manuel del Valle, Manuel Robredo, Casimiro Herránz e hijos, Carlos Sáenz, José López, Clemente Aranjuelo, José Hernáiz, Francisco Perujo, Luis Boulandie, José Armas, Gregorio Hernáinz, Casimiro Labarta, Felipe Lope Robredo y Gregorio García Villar.

51. Tbídem. Prot. not. Ezcaray. Santiago Manuel González Herreros. Sig. 2636, año 1829, fol. 299. Escritura de Compañía y sociedad (30/XIV/1829).

52. Ibídem. Prot. not. Ezcaray. Santiago Manuel González Herreros. Sig. 2636, año 1829, fol. 294 y 295 . «Escritura de venta de varios efectos de máquinas para tundir y perchar, otorgada por D. Carlos Bicheraop, en favor de José Mendiola y Carlos Sáenz Arroyo» (30/XII/1829).

53. Ibídem. Prot. not. Ezcaray. Hermenegildo García. Sig. 2922, año 1843. «Convenio entre Gregorio La Torre vecino de esta villa y D. Pablo Allonard, residente en ésta y de nación francés» (27/V/1843).

54. Ibídem. Prot. not. Ezcaray. Hermenegildo García. Sig. 2839, año 1847, fol. 27. Escritura $(3 / \mathrm{II} / 1847)$. 
Los fondos notariales hasta ahora utilizados, cuando menos nos ofrecen noticias sobre la construcción de cinco nuevos batanes entre los años 1825 y 1853 . El primero fue erigido en 1825 en la próxima localidad de Ojacastro por los fabricantes Felipe García y Juan Antonio Nanclares ${ }^{55}$. En la misma localidad, y probablemente algunos años después, fue levantado otro batán para una sociedad pañera de Ezcaray, en la que el socio más fuerte era D. Manuel Perujo López ${ }^{56}$; y a comienzos de la década de los treinta otro pisón para el también conocido fabricante Carlos Sáenz ${ }^{57}$. Por otra parte, también en el vecino pueblo de Valgañón se levantaron otros dos batanes: uno en el año $1836^{58}$ y el segundo en $1853^{59}$.

En resumen, creemos que tal como indica el profesor Fernández de Pinedo, al hablar del sector textil español durante el primer tercio del siglo XIX, también en Ezcaray la guerra de la Independencia supuso un fuerte contratiempo para las actividades artesanales $^{60}$. Momento tras el cual los fabricantes riojanos, aprovechando la legislación proteccionista del Trienio Liberal y el arancel de 1826, y el «relativo eclipse catalán entre 1812 y $1833^{61}$, se lanzaron por la vía de la mecanización del sector textil, al igual que otras zonas peninsulares no catalanas $)^{62}$.

Ahora bien, aunque este proceso de modernización y mecanización fue en Ezcaray bastante intenso, nunca llegó a ser espectacular. La primera mitad del siglo XIX para la pañería del Alto Oja más exactamente habría que calificarla como una época de imperfecta mecanización. En este sentido todos los documentos notariales utilizados hasta ahora ponen de manifiesto que la industrialización de esta pañería sólo tuvo lugar en las labores del cardado, hilado y en las finales del tundido y apresto. Ni una sola escritura señala la compra o construcción de algún tipo de telar más moderno que los clásicos manuales. Es súmamente significativo que a la altura de 1856 la provincia entonces de Logroño, donde el peso de la comarca de Ezcaray era muy importante, englobara el 26’2 por ciento de los husos manuales y el 4'8 de los mecánicos a nivel nacional en el proceso de la hilatura, así como el 5'5 por ciento de los telares manuales y tan sólo el 0'5 de los mecánicos en las operaciones del tisaje ${ }^{63}$. Porcentajes que sin duda corroboran lo antes

La reseña de Pascual Madoz al referirse a esta zona es realmente iluminadora: «Al principio que se estableció la maquinaria en esta población, no acontecieron sucesos y alborotos desagradables como en otras partes, sin duda por efecto de que esta fabricación

55. Ibídem. Prot. not. Ezcaray. Basilio de Mata. Sig. 2701, año 1825, fol. 435. «Poder de D. Felipe López y Juan Antonio Nanclares, vecinos respectivos de Ezcaray y Oxacastro, a D. Andrés Cortázar, vecino de dho Ojacastro, para mostrarse parte y seguir en el Juzgado de dha villa de Ojacastro, una demanda promovida por D. Angel Vinuesa, de Santo Domingo de la Calzada, sobre construcción de un Batán» (26/IV/1825).

56. Ibídem. Prot. not. Ezcaray. Basilio de Mata. Sig. 2701, año 1825, fol. 141. Poder (5/IX/1825). Y Santiago Manuel González Herreros. Sig. 2636, año 1825, fol. 159 y 160 . Escritura $(6 / I V / 1825)$.

57. Ibídem. Prot. not. Ezcaray. Santiago Manuel González Herreros. Sig. 2889, año 1834, fol. 39. Poder (23/IV/1834).

58. Ibídem. Prot. not. Ezcaray. Santiago Manuel González Herreros. Sig. 2763, año 1836, fol. 52-54. «Escritura de combenio entre D. Florencio Fernández, Julián y Manuel Terna» (27/IX/1836).

59. Ibídem. Prot. not. Ezcaray. Hermenegildo García. Sig. 2745, año 1853, fol. 405. Compromiso.

60. Fernández de Pinedo, Emiliano. Coyuntura y política económicas. Dentro de la obra «Centralismo, Ilustración y agonía del Antiguo Régimen (1715-1833)». Barcelona 1980. p. 110.

61. Ibídem. p. 111.

62. Ibídem.

63. Un siglo de Industrialización catalana. Ob. cit. pp. 79 y 80. 
aun en los tiempos de mayor prosperidad, nunca llegó a ser tan grande que jamás quedasen un crecido número de operarios desocupados o sin trabajo: en el día, y aun hace ya algunos años, es cuando principiaron a experimentar esta desgracia, debida más a las causas que hemos citado que a los adelantos y progresos de la maquinaria, las cuales son las que motivaron principalmente la emigración de muchas personas naturales y forasteras, que deseosas éstas y aquéllas de hallar trabajo continuo se habían avecindado en esta Villa» ${ }^{64}$. Por lo tanto, es posible hablar de esa imperfecta mecanización, complementada con la existencia de numerosas operaciones manuales, sobre todo en el proceso del tisaje ${ }^{65}$.

Es posible, aunque realmente para poder llegar a afirmarlo con seguridad todavía nos faltan muchos datos de carácter cuantitativo, que esta situación se debiera a la entonces muy considerada habilidad de los tejedores ezcarayenses, y a las dificultades surgidas a la hora de encontrar una fuente de energía segura y relativamente barata. No olvidemos que prácticamente todas las máquinas que se introdujeron en la Comarca de Ezcaray eran movidas por agua o por energía de origen animal. La carencia de un combustible como el carbón, tan típico de la Revolución Industrial, ciertamente al igual que había ocurrido en Cataluña pudo haber sido paliado con la utilización de la energía hidráulica; pero esta alternativa no era en Ezcaray todo lo clara que se podía esperar: aunque el Oja y sus arroyos contaban con rápidas corrientes de agua en buena parte del año, sus caudales no eran demasiado grandes, estando sus orillas desde hacía mucho tiempo repletas de molinos, ferrerías y batanes. Así pues la utilización del agua como alternativa energética no contaba con unas posibilidades ilimitadas.

No obstante, la construcción e introducción de diferentes máquinas especialmente durante los años veinte y treinta del siglo XIX, tuvo la virtud, tal como de nuevo ha señalado para muchas zonas del País Fernández de Pinedo, de facilitar «la aparición de talleres destinados a construir y reparar máquinas textiles ${ }^{66}$. Este proceso, apoyado a nivel general en la prohibición británica de exportar maquinaria durante estos años ${ }^{67}$, en nuestro caso se vió muy favorecido por el importante desarrollo que alcanzaron las fundiciones de hierro y sus numerosas fraguas transformadoras ${ }^{68}$.

64. Madoz, Pascual. Diccionario geográfico-estadistico-histórico de España y sus posesiones de Ultramar. Recopilación y reimpresión. Rioja. Logroño 1985. p. 92.

65. Parejo Barranco, J. A. Notas sobre la industria lanera antequerana del siglo XIX (1833-1868). Moneda y Crédito, no 159 , diciembre de 1981. En este trabajo se puede comprobar que también en Antequera, con una vieja tradición pañera, ocurrió algo parecido: «el hilado, mecanizado completamente desde 1862, no sustituyó una maquinaria atrasada -las «mule-jennys»-, y el tisaje continuó realizándose de forma manual: el desfase con otros focos laneros se iba haciendo insalvable». pp. 76 y 77 .

66. Fernández de Pinedo, Emiliano. Ob. cit. p. 111.

67. Ibídem. p. 112.

68. Ojeda San Miguel, Ramón. Algunas notas sobre la Siderometalurgia tradicional riojana. Revista «Berceo». En prensa. 
